\section{Electronic Spectra of Thioformaldehyde and the Methyl Thiyl Radical}

Is the flash photolysis of some simple sulphur containing molecules in the gas phase, we have recently observed several new electronic spectra in absorption. Largely on the basis of chemical evidence from widely different molecular systems, carriers have been assigned to $\mathrm{CH}_{2} \mathrm{~S}$ (thioformaldehyde) and $\mathrm{CH}_{3} \mathrm{~S}$ (methyl thiyl radical). We also comment briefly on some aspects of the kinetics and photochemistry.

Using flash energies up to $2,500 \mathrm{~J}$ and a single optical pass through a $75 \mathrm{~cm}$ long reaction vessel, spectra were recorded with a Hilger medium quartz spectrograph on Ilford HP3 plates sensitized with sodium salicylate. All experiments were conducted at about $293^{\circ} \mathrm{K}$.

Fig. 1 shows spectra in the $210-220 \mathrm{~nm}$ region which were recorded in the flash photolysis of $\mathrm{CH}_{3} \mathrm{SSCH}_{3}$ (dimethyldisulphide). The strong, short lived, feature at $216 \mathrm{~nm}$ is the Herzberg $\mathrm{CH}_{3}$ band ${ }^{1}$, and in addition three new spectra are indicated. The red-shaded band, with a short wavelength head at about $211.75 \mathrm{~nm}$, exhibits a "coarse fine-structure" which seems to be the result of the presence of the $\mathrm{CH}_{2} \mathrm{~S}$ molecule. This species persists for several seconds after flashing. The single, diffuse, band eentred at about $218.5 \mathrm{~nm}$ is assigned to the $\mathrm{CH}_{3} \mathrm{~S}$ radical which has a decay time comparable with that of the $\mathrm{CH}_{3}$ radical. Fig. 1 also shows two narrow bands, disposed one on each wavelength extreme of the $\mathrm{CH}_{3}$ transition, but assignment of this spectrum is still preliminary. The 211.7 nun feature has been observed in the flash photolysis of $\mathrm{CH}_{3} \mathrm{SSCH}_{3}, \mathrm{CH}_{3} \mathrm{SCH}_{3}, \mathrm{CH}_{3} \mathrm{SH}, \mathrm{COS}+$ $\mathrm{CH}_{4}, \mathrm{CH}_{2} \mathrm{~N}_{2}$ (diazomethane) $+\mathrm{COS}, \mathrm{CH}_{2} \mathrm{~N}_{2}+\mathrm{H}_{2} \mathrm{~S}$, and $\mathrm{CH}_{2} \mathrm{~N}_{2}+\mathrm{CS}_{2}$. The $\mathrm{CH}_{3}$ transition was detected in each of the first four molecular systems. In the experiments with $\mathrm{CH}_{2} \mathrm{~N}_{2}$ with either $\mathrm{COS}$ or $\mathrm{H}_{2} \mathrm{~S}$, the intensity of the $211.7 \mathrm{~nm}$ band was independent of the flash energyprovided the diazomethane was entirely photolysed.

From purely chemical evidence unequivocal assignment of the $211.7 \mathrm{~nm}$ band to $\mathrm{CH}_{2} \mathrm{~S}$ is difficult because direct production of $\mathrm{CH}_{2} \mathrm{~S}$ in a primary photochemical process

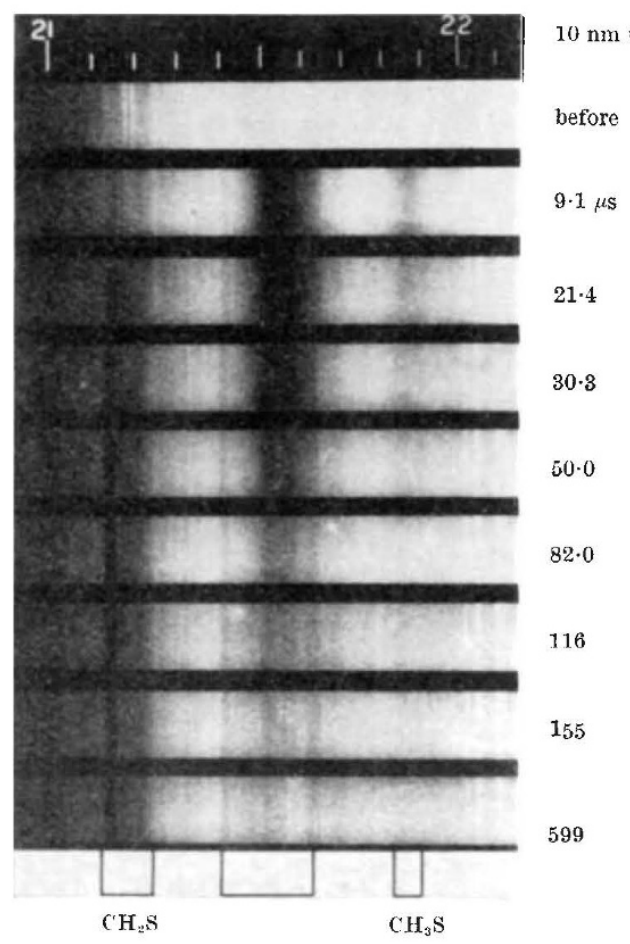

Fig. 1. Transient spectra in flashed dimethyldisulphide. camot be clearly demonstrated. It is ennsidered that the carrier of the band must contain each of the elements $C$, $\mathrm{H}$ and $\mathrm{S}$. The spectrum has been detected only in systems which contain all three elements, and there are no plausible structures to which the band can be attributed which contain only a pair of the elcments.

Production of $\mathrm{CH}_{2} \mathrm{~S}$ by disproportionation of $\mathrm{CH}_{3} \mathrm{~S}$ radicals in the photosensitized decomposition of $\mathrm{CH}_{3} \mathrm{SSCH}_{3}$ has been demonstrated by free-radical mass-spectrometry ${ }^{2}$. The production of $\mathrm{CH}_{2} \mathrm{~S}$ has also been proposed on the basis of end product analysis in static direct-photolysis experiments with $\mathrm{CH}_{3} \mathrm{SSCH}_{3}$ (ref. 3) and in the COS+ $\mathrm{CH}_{4}$ photochemical system ${ }^{4}$ (subsequent to $\mathrm{S}\left({ }^{\prime} \mathrm{D}\right)$ insertion into $\left.\mathrm{CH}_{4}\right)$. It must be formed as a major inter mediate via the $\mathrm{CH}_{3} \mathrm{~S}$ radical in the flash photolysis of the compounds containing the $\mathrm{CH}_{3} \mathrm{~S}$ group. The $211.7 \mathrm{~nm}$ band would seem to correspond to a major product for it can be observed with flash energies down to a fow hundred joules. From a study of the kineties of the diazomethane reactions, we conclude that the carrier of the $211 \cdot 7$ $\mathrm{nm}$ band results from a fast reaction of the $\mathrm{CH}_{2}$ radical either with $\mathrm{COS}$ or $\mathrm{H}_{2} \mathrm{~S}$. The transition complexes can be written respectively $\mathrm{C}_{2} \mathrm{H}_{2} \mathrm{SO}$ and $\mathrm{CH}_{4} \mathrm{~S}$, and the only common fragment with uppropriate properties is $\mathrm{CH}_{2} \mathrm{~S}$. The "coarse fine-structure" of the band appears to correspond to " $\mathrm{K}$ " sub-bands due to quantization of rotation about the axis of low moment of inertia. Analysis of the sub-band structure could not be attempted because of inadequate dispersion. A broad band at $208 \mathrm{~nm}$ detected in absorption following irradiation of dimethyl disulphide in a hydrocarbon glass at $77^{\circ} \mathrm{K}$ has been previously attributed to the $\mathrm{CH}_{2} \mathrm{~S}$ monomer.

The band at $218.5 \mathrm{~nm}$ was observed quite strongly in the flash photolysis of $\mathrm{CH}_{3} \mathrm{SSCH}_{3}, \mathrm{CH}_{3} \mathrm{SCH}_{3}$ and $\mathrm{CH}_{3} \mathrm{SH}$. The maximum intensity of the band approximately coincided with the maximum intensity of the photolytic flash over a wide range of flash energies and initial pressures. We therefore conclude that the carrier is a primary product of the photodecomposition in these experiments and attribute the spectrum to the methyl thiyl radical. Perhaps the assignment is obvious because of the extreme improbability that any other transient species could be produced in roughly equal yield from the three parent compounds.

Incidental to these experiments wo have shown that neither the $\mathrm{CH}_{3}$ spectrum nor that of $\mathrm{CH}_{2} \mathrm{~S}$ is observed in the flash photolysis of $\mathrm{CS}_{2}(210 \mathrm{~nm}$ system) in the presence of $\mathrm{CH}_{4}$. Thus the atomic sulphur must be produced almost entirely in its electronic ground state, which confirms earlior findings ${ }^{6}$.

\section{A. B. Calluear \\ J. CONNOR \\ D. R. DICKSON}

Physical Chemistry Laboratory, Lensfield Road, Cambridge.

liceeived December 23, 1968.

${ }^{1}$ Herzberg, G., and Shoosmith, J., C'anad. J. Phys., 34, 523 (1956).

2 Jones, A., Yamashita, S., and Lossing, I. P., Canad. .J. Chem., 46, 833 (1968).

${ }^{3}$ Steer, R. P., and Knight, A. R., J. Phys, Chem., 72, 2145 (1968).

${ }^{4}$ Gunning, H. F., and Strausz, O. P.. Reactions of Sulphur Atoms, Adr. in Photochem., 4, 143 (Interscience, 1966).

${ }^{8}$ Rosengren, Kj., Acta Chem. Scand., 16, 2284 (1962).

- Callear, A. B., Proc. Roy. Soc., A, 276, 401 (1963).

\section{Ternary Compounds of Uranium-Carbon and the Group VIII A Elements}

TERNARY compounds of uranium and earbon with the first row elements of group VIII A in the periodic table have been known for some time. This is because of the relevance of the appropriate ternary phase relationships 